\title{
A Research Note on the Treatment of Naturally Induced Gangrenous Dermatitis in Chickens by Copper Sulfate
}

\author{
MHH Awaad* \\ Department of Poultry Diseases, Faculty of Veterinary Medicine, Cairo University, Egypt
}

Received: September 24, 2017; Published: October 06, 2017

*Corresponding author: MHH Awaad, Department of Poultry Diseases, Faculty of Veterinary Medicine, Cairo University, Egypt,

\section{Opinion}

The disease condition known as gangrenous dermatitis, avian malignant edema, necrotic dermatitis, gangrenous cellulites or gangrenous dermatomyositis has been described by many investigators [1,2]. Gangrenous dermatitis is a disease of young growing chickens characterized by gangrenous areas of the skin and by severe underlying infectious cellulites. Outbreaks often occur in excessively warm, humid houses [3]. Losses in affected flocks are ranging between 1 and $60 \%$ [4]. Clostridium perfringens type A and Clostridium septicum were blamed as the main etiological agents for this infection [4]. Staphylococci spp and E. coli are also incriminated in this infection [1-3].

Beemer [5] reported on an epizootic of dermatitis in chickens caused by the yeast Rhodotula mucilaginosa. Bal and Dabiya [6] reported on Aspergillus fumigates as the etiological agent of avian dermatitis. The condition occurs in broiler chickens and is frequently associated with high encounter outbreaks in replacement laying stock from 4-16 weeks of age [7] who also concluded that drinking water medication with antibiotics in view of complicated etiology is disappointing. The present note dealt with the use of copper sulfate in treating gangrenous dermatitis in chickens. In the present investigation 3 separate replacement laying chicken flocks suffered from total losses of 2.6.19.2 and 4.5\% in the 3 flocks within a period of 6,10 and 12 weeks respectively due to gangrenous dermatitis did not respond to treatment with zinc bcitracin, ampicillin, oxytetraccline or streptomycin.
Oral treatment with 1:2000 cooper sulfate in drinking water given each other day to the investigated chicken flocks gave good results after the third dose with complete repair of the affected tissues on the 5th dose. Progress in general health condition with cessation of mortalities accompanied the repair of the skin lesion. In spite of the long period supplementation of antibiotics in ration offered to the experimented flocks, progress to the recovery side from gangrenous dermatitis was not obtained except after the use of copper sulfate. A result which merits its effect in the treatment of this infection either alone or complementary to antibiotics.

\section{References}

1. Frazier MN, Parizek WJ, Garner E (1964) Gangrenous dermatitis of chickens. Av Dis 8: 269-273.

2. Saunders JR, Bickford AA (1965) Clostridial infections of growing chickens. Av Dis 9(2): 317-326.

3. Whitman CE, Bickford AA (1979) Avian diseases Manual. American Association of Veterinary Pathologists. Department of Veterinary Microbiology. Texas A and M University college Station, Texas, USA.

4. Gross WB (1972) In Diseases of Poultry. Hofstad et al. $6^{\text {th }}$ Ed Iowa state University Press, USA.

5. Beemer AM, Schneerson Porat S, Kuttin ES (1969) Rhodotorula mucilaginosa dermatitis on feathered parts of chickens. Avian diseases 14(2): 234-239.

6. Bal M, Dabiya SM (1984) Studies on avian dermatitis caused by Asperigillus fumigates. Indian Vet J 3: 188-190.

7. Gordon RF, Jordan FTW (1982) Poultry Diseases $2^{\text {nd }}$ ed Bailliere Tindal, London, England. 


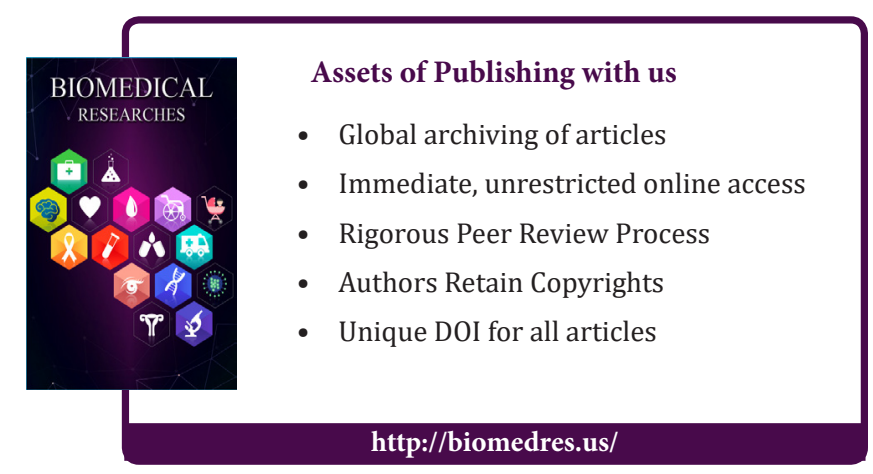

